\title{
O trabalho mediado por plataformas digitais e assimetrias nas relações de comunicação
}

\author{
Claudia Nociolini Rebechi ${ }^{1}$ \\ https://orcid.org/0000-0002-3072-5163
}

\author{
Camilla Voigt Baptistella ${ }^{2}$ \\ https://orcid.org/0000-0001-8232-4954
}

${ }^{1}$ Universidade Tecnológica Federal do Paraná, Departamento Acadêmico de Linguagem e Comunicação, Programa de PósGraduação em Tecnologia e Sociedade, Curitiba, PR, Brasil

${ }^{2}$ Universidade Tecnológica Federal do Paraná, Programa de Pós-Graduação em Tecnologia e Sociedade, Curitiba, PR, Brasil

\section{O trabalho mediado por plataformas digitais e assimetrias nas relações de comunicação}

Resumo: O objetivo deste artigo é discutir sobre as relações de comunicação constituídas no contexto do trabalho de entrega (delivery) mediado por plataformas digitais, considerando especificamente o caso da empresa iFood no Brasil. Trata-se de uma proposta que busca refletir como a referida empresa opta, no projeto e na interface do seu aplicativo, por uma interação limitada com os trabalhadores que realizam a atividade de entrega. Pode-se dizer que, nesse sentido, existe uma assimetria de informação nas relações entre a empresa de plataforma digital e os chamados "entregadores", visto que a empresa possui o monopólio da informação do processo de trabalho gerenciado e controlado algoritmicamente por ela própria. A discussão apresentada neste artigo se apoia em resultados de uma pesquisa empírica realizada com trabalhadores que utilizaram o aplicativo de delivery da empresa iFood na região sul do país, em 2020, no contexto da pandemia de COVID-19.

Palavras-chave: Trabalho; Comunicação; Plataforma digital; IFood. COVID-19.

\section{Work mediated by digital platforms and asymmetries in communication relationships}

Abstract: The aim of this article is to discuss the communication relationships established in the context of food delivery work mediated by digital platforms, specifically considering the case of the iFood company in Brazil. It is a proposal that seeks to reflect how the before-mentioned company chooses, in the design and interface of its app, for a limited interaction with the workers who carry out the delivery work. It can be said that, in this sense, there is an information asymmetry in the relationships between the digital platform company and the so-called "delivery riders", since the company has a monopoly of information in the work process managed and algorithmically controlled by itself. The discussion presented in this article is based on the results of an empirical research carried out with workers who used the iFood company's delivery app in the southern Brazil, in 2020, in the context of the COVID-19 pandemic.

Keywords: Work; Communication; Digital platform; IFood; Covid-19. 


\section{Introdução}

Desde março de 2020, quando a Organização Mundial da Saúde (OMS) declarou oficialmente que estamos vivenciando uma pandemia de COVID-19 ${ }^{1}$, é possível observar uma configuração do mundo do trabalho que incorporou relevantes modificações, impactando severamente formas de trabalhar, relações de trabalho e, consequentemente, a vida de milhões de trabalhadores e trabalhadoras no Brasil.

Devido à necessidade de distanciamento físico entre as pessoas para evitar a transmissão e a contaminação do novo coronavírus, um grande número de empresas, fábricas e estabelecimentos comerciais dos mais diversos setores econômicos interromperam total ou parcialmente suas atividades produtivas. Uma parte dos trabalhadores ligada a essas organizações empresariais precisaram se adequar a novas rotinas de trabalho, com jornadas diárias e remunerações diferenciadas. Outros empregados tiveram que assumir, de modo inesperado, o caráter remoto de sua atividade de trabalho, experimentando obrigatoriamente as dificuldades do chamado trabalho home office. E uma parcela de trabalhadores perdeu seus empregos, avolumando o cenário do desemprego no país que antes da pandemia de COVID-19 já se apresentava grave.

Ao mesmo tempo, o mundo do trabalho brasileiro é conformado por um grande número de trabalhadores que atuam na chamada informalidade ${ }^{2}$, tendo suas vidas ainda mais impactadas negativamente por causa da pandemia. Trata-se de pessoas que realizam diversas atividades de trabalho em busca de remunerações que possam lhe assegurar sua própria sobrevivência e de sua família, sem vínculo empregatício com qualquer organização ou empregador e, portanto, sem poder usufruir dos direitos regulamentados pela Consolidação das Leis do Trabalho (CLT). Muitos trabalhadores e trabalhadoras nesta situação estão impossibilitados ou com grande dificuldade em conseguir qualquer quantia de dinheiro a partir de suas atividades de trabalho, precisando recorrer ao auxílio emergencial do governo federal ou dependendo de ações de filantropia da sociedade civil para sobreviver, a exemplo da distribuição de cestas básicas.

Dentre o conjunto de pessoas que conformam essa parcela da classe trabalhadora, que (sobre)vive do trabalho informal, podemos identificar um grupo específico composto de entregadores por aplicativo. Antes da pandemia de COVID-19, a realização da atividade de trabalho de entrega (delivery) por meio geralmente de motocicletas e bicicletas, e controlada por aplicativos desenvolvidos por grandes corporações conhecidas por suas plataformas digitais, já estava sendo assumida por milhares de brasileiros e brasileiras. Com a pandemia em curso, cresceu a procura por esse tipo de atividade de trabalho, aumentando, ao que tudo indica, o número de entregadores cadastrados nas plataformas digitais proprietárias dos aplicativos de entrega ${ }^{3}$.

Desamparados pelas leis trabalhistas e com o advento da crise sanitária causada pela pandemia de COVID-19, os entregadores por aplicativo estão vivenciando um aprofundamento da precarização de seu trabalho que tem suscitado, de certo modo, uma tensão maior entre esses trabalhadores e as empresas de plataforma. As contradições entre trabalho e capital têm se mostrado mais evidentes, haja vista que essas organizações empresariais recusam em se responsabilizar pelas necessárias condições dignas de trabalho dos entregadores. Além disso, os mecanismos de gestão do trabalho, incluindo as formas de remuneração, controlados pelas plataformas digitais, segundo denúncias dos entregadores ${ }^{4}$, estão prejudicando ainda mais esses trabalhadores durante a atual pandemia.

Diante disso, os conflitos entre trabalhadores e as plataformas digitais se acirraram, trazendo a público, de modo mais explícito, as tensões e as disputas inerentes à lógica algorítmica de um determinado tipo de trabalho digital que se constituiu, em grande medida, com a relação entre esses dois agentes.

Os entregadores, durante a pandemia de COVID-19, realizaram paralisações momentâneas de sua atividade de trabalho ${ }^{5}$ como uma tentativa de serem ouvidos e atendidos pelas empresas de plataformas digitais no que diz respeito às suas reivindicações por condições de trabalho mais dignas e por uma relação mais confiável com o sistema de remuneração e de cadastramento de trabalhadores realizado pelo aplicativo.

É possível dizer, também, que as paralisações dos entregadores explicitaram, dentre outras questões, a carência de interlocução entre as empresas de plataformas digitais e os trabalhadores no processo de gestão do trabalho: "a insuficiência de meios de comunicação com a empresa - quase nunca existe um número de telefone ou um escritório -, faz com que os trabalhadores fiquem à mercê das decisões unilaterais" (ALMEIDA; CARDOSO, 2020, p. 1). Ou seja, os entregadores mostraram que estão insatisfeitos com a relação de comunicação estabelecida pela empresa com eles, a qual prejudica a realização de sua atividade de trabalho e, além disso, os subordina ainda mais ao controle algorítmico imposto pelas plataformas digitais. 
Essa problemática aparece de modo evidente nos resultados da pesquisa empírica realizada por uma das autoras deste artigo (sob a orientação da coautora), em sua dissertação de mestrado ${ }^{6}$ sobre a vigilância e o controle algorítmicos no processo de trabalho do aplicativo de entrega (delivery) da empresa de plataforma digital iFood. Nesse estudo, foram realizadas entrevistas em profundidade com entregadores da região Sul do país que em 2020, já no contexto da pandemia de COVID-19, trabalhavam por meio do aplicativo desenvolvido e gerido pela iFood.

As experiências de trabalho compartilhadas pelos entrevistados revelaram os conflitos inerentes à gestão do trabalho ligada às plataformas digitais e ao uso de aplicativos como uma tecnologia da informação e da comunicação. Tendo isso em vista, neste artigo, nossa proposta é discutir as relações de comunicação constituídas no contexto do trabalho de entrega (delivery) mediado pela plataforma digital iFood no Brasil. Mais especificamente, nossa intenção é pensar e refletir sobre essa questão com base na abordagem sobre a "assimetria de informação" (ROSENBLAT; STARK, 2016). Essa ideia trata da coleta e do processamento de dados pelas plataformas digitais com o propósito de viabilizar a gestão algorítmica do processo de trabalho, considerando a implementação automática de suas diretrizes organizacionais e refletindo o desequilíbrio do conhecimento sobre o processo de trabalho entre plataforma e trabalhador.

Para o alcance do objetivo deste artigo, optamos por um percurso teórico-metodológico que considerou uma análise de depoimentos proporcionados pelas entrevistas em profundidade realizadas na pesquisa empírica da investigação de Baptistella (2021), as quais demostraram as dificuldades relacionadas à comunicação que os entregadores enfrentam para a realização de sua atividade diária de trabalho com base no que eles consideram falta de suporte da empresa iFood.

Diante de tudo isso, este artigo está estruturado do seguinte modo: primeiramente, explicaremos algumas características importantes sobre a natureza e a atuação das empresas de plataformas digitais e o processo de trabalho vinculado a elas. Em seguida, trataremos sobre a caracterização que a empresa iFood atribui à sua relação com os entregadores, considerando aspectos comerciais a fim de refutar a visível subordinação do trabalho e de trabalhadores à referida plataforma digital. Esses dois primeiros momentos do desenvolvimento do artigo são necessários para uma melhor compreensão da reflexão que apresentaremos mais adiante sobre a assimetria de informação com base nos relatos de cinco entrevistas realizadas no estudo de Baptistella (2021). Vale esclarecer que essa pesquisa empírica foi aprovada pelo Comitê de Ética da Universidade Tecnológica Federal do Paraná (CAAE 29497420.9.0000.5547) e realizada no segundo semestre de 2020. Em respeito aos procedimentos metodológicos assumidos nessa investigação, não serão divulgados os nomes dos entrevistados e eles serão, aqui, nomeados pelos seguintes pseudônimos: Bruno, César, Jarbas, Afonso e Luciano.

\section{O trabalho humano explorado pelas plataformas digitais}

Dificilmente alguma pessoa, no Brasil, que more em regiões metropolitanas desconhece a figura do entregador por aplicativo. Dirigindo uma motocicleta ou andando de bicicleta ou até mesmo a pé pelas ruas e avenidas, dia e noite, todos os dias, inúmeras pessoas, atualmente, realizam a atividade de trabalho de entrega de produtos sob demanda. O consumidor solicita o serviço de entrega por meio de aplicativos desenvolvidos por plataformas digitais (ou empresas de plataforma digital) e recebe, das mãos dos entregadores, os seus produtos que, geralmente, também foram comprados por meio dos mesmos aplicativos.

Uber Eats, Rappi e iFood são algumas das mais conhecidas plataformas digitais que atuam no Brasil e têm sob a sua gerência milhares de entregadores que levam às pessoas, especialmente, produtos alimentícios. Em pouco tempo de existência ${ }^{7}$, essas empresas conseguiram tornar seus aplicativos muito conhecidos, tendo sido já utilizados por milhões de consumidores.

Considerado como trabalho digital (CASILLI, 2019) ou trabalho de plataforma (VAN DOORN, 2017), o trabalho realizado com o uso de aplicativos e subordinado ao gerenciamento de plataformas digitais, tal como o dos entregadores, está presente em vários países do mundo. Surgido antes nos Estados Unidos e em países europeus, esse tipo de trabalho ligado às plataformas sob demanda começa a ser incorporado de modo mais evidente ao mundo do trabalho brasileiro em 2014, com o início das operações da empresa Uber Technologies Inc. (UBER, 2020) no país. 
Desde então, a forma de trabalhar a partir do uso de tecnologias da informação e da comunicação, a exemplo dos aplicativos (conhecidos também por apps), começa a ser conhecida e assumida por milhares de brasileiros e brasileiras que encontram, nas tecnologias digitais desenvolvidas pelas empresas de plataforma, uma nova possibilidade de conseguir alguma remuneração com a oferta da sua força de trabalho. Inúmeros serviços, atualmente, são ofertados por meio de diferentes plataformas digitais sob demanda, sendo o transporte de passageiros e a entrega de produtos alimentícios os mais conhecidos e utilizados.

As plataformas sob demanda se apresentam como empresas de tecnologia que criam aplicativos para conectar os entregadores (tratado pelas plataformas como usuários prestadores de serviços e profissionais independentes) e os consumidores (ou clientes finais). Isto é, elas se posicionam como empresas que estabelecem apenas uma mediação entre ambas as partes: os consumidores que compram pelo aplicativo e aqueles disponíveis para realizar a entrega da compra. Neste contexto, as plataformas digitais se recusam a estabelecer qualquer vínculo empregatício com os entregadores, procurando se isentar de possíveis responsabilidades quanto às condições de trabalho e aos direitos legais dos trabalhadores.

No entanto, é difícil contestar a compreensão de que as plataformas digitais gerenciam o trabalho dos entregadores. Pois, são seus aplicativos, submetidos a uma determinada lógica algorítmica criada pelas empresas, que determinam, por exemplo: quais entregas serão realizadas; a frequência das entregas e sua localização; que remuneração o entregador receberá por entrega realizada; quem pode ser cadastrado (e permanecer) no aplicativo. Existe uma série de normas estabelecidas pelas empresas a serem seguidas obrigatoriamente pelos entregadores, as quais estão indicadas nos "termos de uso" das plataformas aceitos por eles e que prescrevem a gestão de seu trabalho.

Esses termos de uso ou termos de serviços são um instrumento que oferecem muito poder às plataformas, deixando os entregadores vulneráveis aos interesses das empresas. Os proprietários dessas plataformas se reservam no direito de modificar este contrato quando lhes for conveniente e muitos acordos previstos neste tipo de documento possibilitam que as empresas encerrem as contas dos trabalhadores cadastradas nos aplicativos sob a justificativa que eles infringiram normas aceitas (VAN DOORN, 2017).

Pode-se dizer que esse tipo de trabalho digital revela uma dependência evidente dos trabalhadores em relação à plataforma. Além dos aspectos prescritos pelas empresas indicados antes, as plataformas criam maneiras de envolver os entregadores à racionalidade do trabalho digital por meio de incentivos econômicos (prêmios por performance), recompensando aqueles que disponibilizam seu tempo, seu esforço físico, sua saúde e sua subjetividade para a realização da atividade de trabalho e penalizando aqueles que estão menos disponíveis para serem explorados (CASILLI, 2019). Em complemento as essas formas de administração do trabalho dos entregadores, as empresas de plataforma também transferem a responsabilidade pela qualificação do trabalho dos entregadores por meio de avaliações do serviço de entrega atribuídas pelos consumidores.

Sabemos que esse tipo de trabalho digital também é realizado em países do Norte global, considerados desenvolvidos, mas, no Brasil, as empresas de plataforma se aproveitam de um contexto econômico, político e social ainda mais favorável para os seus negócios com a flexibilização das leis trabalhistas, a existência ampla da informalização do trabalho, o alto nível de desemprego e as profundas desigualdades sociais e econômicas que afetam diretamente as vidas da maior parcela da população brasileira (ABÍLIO, 2020a).

\section{Os termos de uso do app e a relação de trabalho}

Ao voltarmos nosso olhar para a plataforma digital iFood, conhecida pela sua atuação no segmento de delivery e uma das mais relevantes neste setor no cenário nacional, seu posicionamento em relação aos

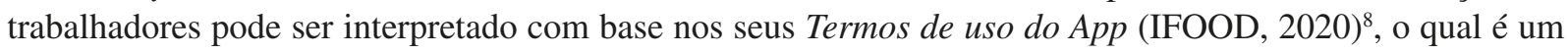
contrato que norteia os papeis desempenhados pelas partes (empresa e entregadores) nessa relação.

Para se tornar um entregador da iFood, primeiramente, é preciso haver a "adesão voluntária indispensável" (IFOOD, 2020, seção 1.1) aos referidos termos para a atuação do trabalhador no aplicativo. A discordância 
com o contrato inviabiliza a possibilidade de ativação do cadastro e a disponibilidade de ofertas de entregas por meio da plataforma.

Essa postura reforça a argumentação da empresa em tratar os entregadores não como trabalhadores da plataforma, mas como aderentes para a integração com a empresa que "compartilha" pedidos de entrega (IFOOD, 2020, seção 1.1). Os entregadores são considerados como usuários, parceiros ou clientes da plataforma, da mesma maneira que os estabelecimentos e os clientes finais, ou seja, como partes de uma relação comercial com o iFood.

Na realidade, os termos explicitam que "os Entregadores, desde já, reconhecem que a relação jurídica estabelecida por estes Termos não cria vínculo empregatício, societário, de associação, mandato, franquia, ou de qualquer outra natureza entre o iFood e os Entregadores" (IFOOD, 2020, seção 2.7, grifo nosso). A justificativa da empresa para isso advém da alegação da plataforma ser uma empresa de tecnologia, desprendendo-se, portanto, da operacionalização de atividades específicas que a corporação realiza e especificando a relação de trabalho como autônomo e/ou independente. Consequentemente, a plataforma consegue evitar sua responsabilização com o vínculo empregatício, garantindo as reduções nos seus custos (DE STEFANO, 2015). O discurso da neutralidade tecnológica colabora para ofuscar a relação de trabalho ao mesmo tempo que torna opaca a intensificação dessa mesma relação.

No entanto, as plataformas precisam das corridas de entrega para existirem, logo, dependem dos entregadores para a concretização do seu negócio. Além disso, essas empresas coordenam e controlam as alocações das atividades e determinam o modo como a operacionalização deve ocorrer. Exemplo disso pode ser notado quando a iFood estabelece o tempo para o entregador chegar ao local da coleta, sendo que a extrapolação desse prazo acarreta a desalocação do pedido sem remuneração.

Essa gerência detida pela empresa pode ser também pensada a partir do conceito de assimetria de informação presente nas reflexões de Alex Rosenblat e Luke Stark (ROSENBLAT; STARK, 2016). A retórica da plataforma digital de ser apenas uma empresa de tecnologia não se verifica. E, ao que nos parece, a iFood apresenta uma contradição entre "[...] a estrutura de emprego e hierarquia que emerge do seu projeto de software e de interface" (ROSENBLAT; STARK, 2016, p. 3762, tradução nossa) ${ }^{9}$, revelando a autonomia reduzida dos entregadores no processo de trabalho.

Essa estrutura organizada pela empresa quanto à atividade desempenhada pelos entregadores reflete as divergências das informações em posse da empresa em relação ao trabalho deles. $\mathrm{O}$ aplicativo desenvolvido pelas empresas de plataforma digital, por meio dos algoritmos, coleta, classifica e processa inúmero dados para coordenar o processo de trabalho e influenciar os comportamentos dos trabalhadores, enquanto esses não possuem acesso à empresa. O discurso da neutralidade da tecnologia colabora para que essa assimetria de informação fique opaca, visto que as tecnologias possuem valores que são inviabilizados por esse imaginário (BUCHER, 2018; GILLESPIE, 2018; JURNO; DALBEN, 2018).

Isso significa que o conceito de assimetria de informação possibilita a interpretação da decisão da iFood em não disponibilizar, como uma estratégia de gestão algorítmica organizacional por exemplo, um canal de comunicação satisfatório para os entregadores contatarem a empresa. Segundo os referidos autores, a assimetria de informação é estabelecida por uma estrutura de controle possibilitada pelo gerenciamento algorítmico que é inerente ao projeto do aplicativo e também à sua interface. Isso ocorre devido ao monopólio da informação que as plataformas digitais detêm do processo de trabalho dos entregadores e por causa do poder que elas exercem sobre ele.

Desse modo, Rosenblat e Stark (2016) compreendem a gestão algorítmica para além da coleta de dados, dos hábitos e comportamentos, e engloba também a implementação automática das diretrizes da empresa sobre o processo de trabalho. Essas determinações dizem respeito à maneira como a empresa iFood espera que o processo de trabalho seja executado. Para uma melhor compreensão dessa questão, podemos retomar o exemplo já apresentado sobre o tempo estipulado pela plataforma para o entregador chegar ao local da coleta após o aceite da rota ou ainda trazer à tona pontos dos termos de uso que tratam sobre o bloqueio ou a desativação como reflexo de "recorrentes avaliações negativas" (IFOOD, 2020, seção 9.3). Portanto, a assimetria de informação entre empresa e entregador são aspectos da concepção dos aplicativos a fim de imporem e exercerem uma gamificação e também um controle suave sobre o processo de trabalho (ROSENBLAT; STARK, 2016). 


\section{Relações de comunicação assimétricas entre a empresa Ifood e os entregadores}

Enquanto as plataformas digitais podem se comunicar com os entregadores através do aplicativo próprio, de SMS, do e-mail e mesmo pelo aplicativo Whatsapp, os trabalhadores não conseguem ter um fácil acesso à empresa, conforme já exposto.

As entrevistas realizadas para a pesquisa de mestrado (Baptistella, 2021) evidenciaram uma dificuldade dos entregadores de se comunicarem com a empresa iFood via o seu aplicativo. À época dessa pesquisa, segundo semestre de 2020, os únicos canais de atendimento que os entregadores afirmaram conseguir usar para falar com a referida plataforma eram o chat, disponibilizado durante a realização de uma entrega, e a possibilidade da abertura de um "chamado" no aplicativo.

Tratemos, primeiramente, dos chamados, os quais, vale esclarecer, estão atrelados a uma espécie de seção de ajuda do aplicativo com respostas prontas para questões comuns. No entanto, como aponta o entrevistado Jarbas: "é claro que a filtragem ajuda muito, mas faz falta, para muitos casos, um 0800 igual ao que a Ubereats tem". As respostas automáticas fornecidas pelo aplicativo podem ser interpretadas como a ausência de uma supervisão humana do processo de trabalho, em certa medida, conforme comentou César: "o iFood, infelizmente, não são pessoas que respondem a gente. É o sistema. É tudo automático".

Desse modo, os entrevistados, em seus relatos, evidenciaram como as formas de comunicação estabelecidas pela empresa na interlocução com os entregadores não os auxiliam na realização concreta e cotidiana do trabalho. O entrevistado Bruno evidenciou este fato ao relatar como a empresa iFood não provê uma assistência às necessidades específicas de cada trabalhador:

\footnotetext{
Você não tem suporte, você tem chamado. Você abre lá para tirar uma dúvida, por exemplo, tipo bagulho de acidente ou você quer falar de alteração de documento, alteração de cadastro, essas coisas. Você não tem contato direto para falar com alguém dentro do aplicativo. Você tem que abrir um chamado, que é como você abrir um e-mail, e eles respondem quando der na telha. Esse é o suporte que a gente tem. A gente não consegue falar com ninguém diretamente dentro do aplicativo.
}

No que diz respeito ao chat (disponível apenas durante a realização de uma rota), também os entrevistados sentiram desamparo e o distanciamento por parte da empresa, conforme comentou o entregador Jarbas:

O iFood, por chat, para ele te atender, nossa cara, demora. Até eles te responder: demora, demora, demora. Cada resposta tua tem um tempinho para eles te responderem. Nisso você fica ali resolvendo em um chat, que não é nem um telefone, você fica respondendo um chat. E, às vezes, não te ajudam e eles dizem assim “ah, eu consegui te ajudar?", às vezes, eu digo "não, não conseguiu”. E aí? Você fica com o problema na mão por falta de suporte de verdade.

Esses relatos dos trabalhadores indicam a limitação de interação entre o entregador e a empresa e, ao mesmo tempo, mostram que as possibilidades que os trabalhadores têm para contatar a empresa são insuficientes. Essa questão revela a própria opção da empresa quanto à arquitetura da estrutura do aplicativo, visto que a plataforma digital detém informações que os entregadores não possuem (ROSENBLAT; STARK, 2016).

Além disso, isso demonstra como as plataformas dependem de um exército de trabalhadores disponível para a viabilidade dessa gestão do trabalho que é algorítmica. Quanto mais trabalhadores disponíveis e necessitados de trabalho, mais a empresa, por meio da gestão algorítmica, transfere os riscos, as responsabilidades e os custos aos entregadores devido à assimetria de informação e ao poder que ela detém ao coordenar, gerir sem qualquer regulamentação do Estado. As empresas de plataforma digital decidem como a relação de trabalho deve ser estabelecida, refletindo, portanto, a disparidade das partes do contrato. De acordo com Ludmila Abílio (2020, p. 14), o gerenciamento algorítmico permite que a multidão de trabalhadores seja gerenciada "de forma centralizada e monopolizada". O que é percebido pela já referida adesão ao contrato. Assim, "tornouse possível, de forma administrada, racionalizada e produtiva, converter uma multidão de trabalhadores em trabalhadores informais que estão disponíveis ao trabalho, mas só são utilizados na medida determinada pelas próprias empresas" (ABILIO, 2020, p. 18).

Verificamos essa disponibilidade de trabalhadores no depoimento do entrevistado Luciano que foi desativado permanentemente da plataforma no início de 2020: "no dia que o iFood me bloqueou, eu tava 
correndo atrás, né. Mas tu achas que para o iFood eu vou fazer falta? Lógico que não, porque eu saio e tem 30, tem 50, tem mais de 100 pessoas na espera. [...] Para o aplicativo a gente só é um número".

Luciano também contou que sua desativação permanente - ao que ele pode identificar, visto que a empresa nunca justificou a exclusão da sua conta - aconteceu por causa da não localização do cliente para a entrega de um pedido. Ao não conseguir contatar o cliente, o motoboy entrou em contato com o suporte do iFood e, como alegou, ficou mais de 40 minutos esperando as orientações da empresa (tempo que não lhe foi remunerado). Nesse caso, a empresa instruiu o motoboy a retornar o pedido ao restaurante, sendo acatado pelo entregador. No entanto, no dia seguinte ao acontecimento, Luciano recebeu a informação da desativação definitiva de sua conta no aplicativo, mas não obteve nenhuma justificativa por parte da empresa sobre o seu desligamento e, além disso, ele diz que não teve a possibilidade de recorrer dessa decisão.

As desativações permanentes de trabalhadores são recorrentes, sendo que as mensagens da plataforma apenas apresentam que alguma infração dos termos aconteceu, sem expor quais seriam, de fato, essas infrações. Podemos dizer, portanto, que existe uma prática de relação de poder sobre o processo de trabalho e a falta de autonomia de quem trabalha. A inviabilidade de um diálogo com cada trabalhador é uma forma da empresa impor suas determinações em detrimento dos eventos e das situações específicas de cada processo de trabalho. O entrevistado César comentou sobre isso ao dizer: "se você vai atrasar a entrega ou alguma coisa assim, você não tem como conversar e explicar a tua situação, simplesmente é o que eles impõem lá e você tem que aceitar uma das opções".

Os trabalhadores buscam uma interlocução com a empresa por meio dos canais de comunicação oficial que ela disponibiliza. Contudo, quando eles não têm êxito, os sites de reclamações disponibilizados por outras empresas aparecem como um canal de comunicação possível com a iFood. O Reclame Aqui ${ }^{10}$, por exemplo, foi citado durante as entrevistas com essa finalidade.

A empresa iFood possui, nesse site de reclamação, uma atuação importante, contribuindo para ter quase todas as reclamações direcionadas a ela respondidas, tendo uma taxa de avaliação de 8.9 que se refere ao período de dezembro de 2020 a maio de 2021 (RECLAME AQUI, 2021). Levando em conta que os canais de comunicação oficiais da iFood são, de certo modo, inviabilizados na própria estrutura organizacional da plataforma, o Reclame Aqui pode ser considerado um canal não oficial que os próprios entregadores encontraram para se expressarem e estabelecerem uma relação de comunicação com a empresa. O entregador Afonso explicou sobre esse uso: "quando você vai lá no Reclame Aqui e começa a falar mal deles, eles entram em contato para perguntar o que está acontecendo. Só que quando é para você falar com eles pelo telefone ou pelo chat, você não consegue, porque não tem um meio de comunicação".

Entretanto, conforme o entrevistado Bruno também relatou, o contato estabelecido via o site Reclame Aqui não é, tampouco, garantia de respostas claras por parte da empresa iFood:

Eu tinha feito um "Reclame Aqui" também, eles me responderam, mas não me deram respostas do que eu queria [saber]. Eu falei que tinha sido bloqueado, que não tinha motivo, e que eu queria saber o porquê. Eu só queria uma resposta. Eles me responderam pelo "Reclame Aqui", falaram que, provavelmente, eu tinha feito alguma coisa grave, porque, se realmente eu fui bloqueado, pode ter certeza que eu vou descobrir o porquê e não sei o quê. Mas nunca tive resposta.

Ao que nos parece, a empresa não procura esclarecer ou estabelecer uma relação recíproca com os trabalhadores, mas apenas tenta minimizar os impactos negativos que uma reclamação no site "Reclame Aqui" pode ter sobre a sua marca no resultado de buscadores da internet. As ações da iFood aparentam ser mais uma retórica do que um posicionamento efetivo em resolver os problemas dos trabalhadores, visto que a falta de um canal de comunicação efetivo expõe a assimetria de informação, logo a desigualdade na relação entre a plataforma e os entregadores. A empresa detém a informação e exerce a gerência sobre o processo de trabalho cotidiano, impondo as diretrizes de como o trabalhador deve proceder na realização da atividade. Isso nos faz lembrar algo que Harry Braverman (1987, p. 168) já disse tempos atrás: “[...] além de sua função técnica de aumentar a produtividade do trabalho - que seria uma característica da maquinaria em qualquer sistema social -, a maquinaria tem também no sistema capitalista a função de destituir a massa de trabalhadores de seu controle sobre o próprio trabalho." 
A adesão dos trabalhadores aos termos de uso, que implica na aceitação das determinações contratuais unilaterais da plataforma, torna evidente as imposições da organização ao trabalhador. E mais ainda quando notamos que a empresa declara a inexistência de vínculo de trabalho. Os instrumentos técnicos desenvolvidos e implantados pela corporação ofuscam a assimetria de informação, logo, o controle que a empresa possui do processo de trabalho de entregas. Os trabalhadores, sob a nossa compreensão, têm autonomia limitada na execução da atividade de entrega, o que fica exposto quando refletimos a estrutura de comunicação construída e disponibilizada pela empresa, revelando, por fim, a sua subordinação à empresa.

\section{Considerações finais}

Por meio da extração, do armazenamento e do uso dos dados das pessoas, as empresas proprietárias de plataformas digitais tornaram-se poderosas ao conseguirem criar uma lógica de gestão algorítmica do trabalho nunca antes vista. Trata-se de uma lógica que procura ocultar a atividade humana de trabalho, atribuindo uma suposta neutralidade às tecnologias da informação e da comunicação desenvolvidas pelas empresas. Nesse sentido, as empresas de plataforma digitais tentam invisibilizar a importância do trabalho humano indispensável para o funcionamento e a manutenção de seu modelo de negócios.

Neste artigo, foi possível discutir, a partir do caso da empresa iFood, que a assimetria de informação é resultado do poder decisório sobre o trabalho executado pela plataforma digital, tanto no âmbito da oferta e demanda do trabalho, dos preços, da localização, quanto em relação à estrutura de comunicação disponível aos trabalhadores pela empresa. A ausência de um canal de comunicação satisfatório que possibilite a manifestação dos problemas da atividade de trabalho pelos próprios trabalhadores evidencia a relação desigual entre as partes (plataforma e entregador), já que as informações necessárias à execução do processo de trabalho estão acessíveis à plataforma para a concretização do gerenciamento algorítmico. Os trabalhadores não recebem retornos da empresa e nem possuem acesso às métricas da sua atividade de trabalho, tampouco possuem formas de contra-argumentar sobre as decisões unilaterais da empresa. Esses sujeitos estão a mercê das determinações da plataforma para a execução do seu trabalho.

A relação de comunicação precária estabelecida pela plataforma digital com os entregadores, por sua vez, somente é possível devido ao fato de haver um exército de trabalhadores disponível a seguir as condições impostas pela empresa, dado que sua sobrevivência depende do encaminhamento de pedidos dos usuários do aplicativo, o qual é gerido pela plataforma. A assimetria de informação entre a plataforma e o entregador contribui para que o trabalhador tenha uma autonomia limitada sobre o processo de trabalho que realiza, ou seja, ela evidencia o controle que a iFood possui sobre a atividade de entrega, revelando a subordinação à qual o trabalhador está submetido.

\section{Referências}

ABILIO, L. C. et al. Condições de trabalho em empresas de plataforma digital: os entregadores por aplicativo durante a Covid-19. São Paulo: REMIR, 2020.

ABILIO, L. C. Plataformas digitais e uberização: a globalização de um Sul administrado? Revista Contracampo, [S. 1.], v. 39, n. 1, 2020.

ABILIO, L. C. Uberização: a era do trabalhador just-in-time? Estudos Avançados, São Paulo, v. 34, n. 98, p. 111-126, 2020a.

ALMEIDA, P. F.; CARDOSO, A. C. M. A essência rebelde do "Breque dos Apps”. Outras Palavras, São Paulo, 8 jul. 2020. Disponível em: https://outraspalavras.net/outrasmidias/a-essencia-rebelde-do-breque-dos-apps/. Acesso em: 23 fev. 2021.

BAPTISTELLA, Camilla Voigt. Pra quem tem fome: vigilância e controle algorítmicos no processo de trabalho de um aplicativo de entrega em Curitiba. 2021. Dissertação (Mestrado em Tecnologia e Sociedade) - Universidade Tecnológica Federal do Paraná, Curitiba, 2021. Disponível em: http://repositorio.utfpr.edu.br/jspui/handle/1/25400. Acesso em: 27 jun. 2021.

BRAVERMAN, H. Trabalho e capital monopolista: a degradação do trabalho no século XX. Rio de Janeiro: LTC, 1987.

BUCHER, T. Algoritmos como um devir: uma entrevista com Taina Bucher. Parágrafo, [S. 1.], v. 6, n. 1, p. 165-170, 2018.

CASILLI, A. En attendant les robots: enquête sur le travail du clic. Paris: Seuil, 2019.

DE STEFANO, V. The Rise of the "Just-in-Time Workforce": On-Demand Work, Crowd Work and Labour Protection in the "GigEconomy”. SSRN Electronic Journal, [S. 1.], 2015. Disponível em: http://www.ssrn.com/abstract=2682602. Acesso em: 31 jan. 2020. 
GILLESPIE, T. A relevância dos algoritmos. Parágrafo, [S. 1.], v. 6, n. 1, p. 95-121, 2018.

IFOOD. Termos de uso do App. Portal do Entregador. 2020. Disponível em: https://entregador.ifood.com.br/termosdeuso/. Acesso em: 16 ago. 2020 .

JURNO, A. C.; DALBEN, S. Questões e apontamentos para o estudo de algoritmos. Parágrafo, [S. 1.], v. 6, n. 1, p. 17-29, 2018.

OLIVEIRA, C. et al. Tudo no aplicativo. Exame, São Paulo, n. 1183, p. 18-29, 2019.

OLIVEIRA, F. De. Crítica à razão dualista / O ornitorrinco. São Paulo: Boitempo, 2003.

RECLAME AQUI. iFood - Reclame Aqui. 2021. Disponível em: https://www.reclameaqui.com.br/empresa/ifood/. Acesso em: 22 jun. 2021.

ROSENBLAT, A.; STARK, L. Algorithmic Labor and Information Asymmetries: A Case Study of Uber's Drivers. International Journal of Communication, [S. 1.], v. 10, p. 3758-3784, 2016.

TRABALHADOR enfrenta fila de espera para se tornar entregador em aplicativos. Época Negócios, São Paulo, 19 jul. 2020. Disponível em: https://epocanegocios.globo.com/Carreira/noticia/2020/07/epoca-negocios-trabalhador-enfrenta-fila-de-espera-para-se-tornarentregador-em-aplicativos.html. Acesso em: 29 jun. 2021.

UBER. Fatos e Dados sobre a Uber. Brasil, 27 ago. 2020. Disponível em: https://www.uber.com/pt-BR/newsroom/fatos-e-dadossobre-uber/. Acesso em: 7 set. 2021.

VAN DOORN, N. Platform labor: on the gendered and racialized exploitation of low-income service work in the "on-demand" economy. Information, Communication \& Society, [s.1.] v. 20, n. 6, p. 898-914, 2017.

\section{Notas}

1 Este artigo foi escrito em junho de 2021. Ou seja, faz mais de um ano, desde o anúncio da Organização Mundial da Saúde (OMS) sobre a pandemia de COVID-19, que estamos sob a recomendação de isolamento social no Brasil.

2 O professor Francisco de Oliveira (2003, p. 136) já apontou tempos atrás que: “o setor informal apenas anuncia o futuro do setor formal”, dado que nas últimas décadas do século XX existiram transformações na produtividade do trabalho como consequência de novas tecnologias e da mundialização. Nesse sentido, podemos identificar os resultados anunciados pelo trabalho via plataformas digitais em que "o conjunto de trabalhadores é transformado em uma soma indeterminada de exército da ativa e de reserva, que se intercambiam não nos ciclos de negócio, mas diariamente” (OLIVEIRA, 2003, p. 136).

3 De acordo com uma matéria da revista Época Negócios de 2020, o volume de novos cadastros no aplicativo iFood aumentou consideravelmente nos primeiros meses da pandemia, revelando que em fevereiro de 2020 os entregadores ativos eram 131 mil, enquanto que "em março, os entregadores passaram a 170 mil". A matéria ainda comenta que a plataforma Rappi aumentou em 128\% o número de entregadores em abril de 2020 comparado com o mesmo período em 2019 (TRABALHADOR..., 2020, p. 1).

4 A pesquisa realizada em 2020 pela Rede de Estudos e Monitoramento Interdisciplinar da Reforma Trabalhista (REMIR) apontou que durante a pandemia houve um aumento na quantidade de horas trabalhadas nesse setor, o qual não foi acompanhado pela remuneração. Isso reflete a dependência desses trabalhadores do encaminhamento de pedidos conforme os mecanismos estipulados pela plataforma: "para aqueles que trabalharam, durante a pandemia, mais de 15 horas, 78,6\% relata que seu rendimento caiu e 21,4\% que se manteve" (ABILIO et al., 2020, p. 8).

5 Dentre as paralisações realizadas por entregadores em 2020 está o "Breque dos apps" de 1 de julho, (ALMEIDA; CARDOSO, 2020).

6 Trata-se da dissertação de autoria de Baptistella (2021), que foi realizada no Programa de Pós-Graduação em Tecnologia e Sociedade (PPGTE) com o apoio da Coordenação de Aperfeiçoamento de Pessoal de Nível Superior - Brasil (CAPES) - Código de Financiamento 001 - por meio de bolsa de mestrado. A referida pesquisa está disponível na íntegra no repositório da biblioteca da Universidade Tecnológica Federal do Paraná (UTFPR) e pode ser acessada em: http://repositorio.utfpr.edu.br/jspui/handle/1/25400.

7 Para se ter uma dimensão do crescimento da atuação comercial das plataformas digitais, a empresa Uber chegou ao Brasil em 2014 e já em 2019 o país era o "segundo maior mercado da Uber no mundo, atrás apenas dos Estados Unidos, com cerca de 600.000 motoristas" (OLIVEIRA et al., 2019, p.1).

8 O atual termo de uso disponível aos entregadores é de 24 de novembro de 2020. Entretanto, para nossa argumentação neste artigo, fizemos uso da versão de julho de 2020.

9 No original: “[...] employment structures and hierarchies that emerge through its software and interface design" (ROSENBLAT; STARK, 2016, p. 3762).

10 Trata-se de uma página na internet com o propósito de avaliar a reputação de empresas com base nas declarações das experiências dos consumidores em relação aos produtos, aos serviços e ao atendimento. Dessa maneira, o Reclame Aqui é utilizado por muitas empresas como uma plataforma de gestão da imagem da marca para os consumidores. 
Claudia Nociolini Rebechi

claudiarebechi@utfpr.edu.br

Doutora pelo Programa de Pós-Graduação em Ciências da Comunicação pela Universidade de São Paulo (USP)

Docente do Departamento Acadêmico de Linguagem e Comunicação (DALIC) e do Programa de Pós-

Graduação em Tecnologia e Sociedade (PPGTE) na Universidade Tecnológica Federal do Paraná (UTFPR)

\title{
UTFPR
}

Av. Sete de Setembro, 3165, Rebouças

Curitiba - PR-Brasil

CEP: 80230- 901

\section{Camilla Voigt Baptistella}

camilla.vbap@gmail.com

Graduada em Ciências Econômicas pela Pontifícia Universidade Católica de São Paulo (PUC-SP) e mestra pelo Programa de Pós-Graduação em Tecnologia e Sociedade (PPGTE) na Universidade Tecnológica Federal do Paraná (UTFPR)

\section{UTFPR}

Av. Sete de Setembro, 3165, Rebouças

Curitiba - PR- Brasil

CEP: 80230- 901

\section{Agradecimentos}

Agradecemos aos trabalhadores que se disponibilizaram a participar da pesquisa empírica que embasou este artigo, cujas contribuiç̃oes foram de grande importância para o conhecimento da realidade investigada.

Agência financiadora

Não se aplica.

\section{Contribuições das autoras}

Neste artigo, ambas as autoras contribuíram com a concepção da proposta, o desenvolvimento da discussão teórica, a interpretação dos dados, a redação do manuscrito e a revisão do texto.

\author{
Aprovação por Comitê de Ética e consentimento para \\ participação \\ A pesquisa (CAAE 29497420.9.0000.5547) foi aprovada pelo \\ Comitê de Ética em Pesquisa da Universidade Tecnológica \\ Federal do Paraná, mediante parecer N. 4.198.080, emitido em \\ 06 de agosto de 2020. Foi utilizado Termo de Consentimento \\ Livre e Esclarecido. \\ Consentimento para publicação \\ Consentimento das autoras. \\ Conflito de interesses \\ Não há conflito de interesses.
}

